\title{
Anti-nucleosome Antibodies Complexed to Nucleosomal Antigens Show Anti- DNA Reactivity and Bind to Rat Glomerular Basement Membrane In Vivo
}

\author{
C. Kramers, ${ }^{*}$ M. N. Hylkema, ${ }^{\ddagger}$ M. C. J. van Bruggen, ${ }^{\star}$ R. van de Lagemaat, ${ }^{\ddagger}$ H. B. P. M. Dijkman, ${ }^{5}$ K. J. M. Assmann, ${ }^{\S}$ \\ R. J. T. Smeenk, ${ }^{\ddagger}$ and J. H. M. Berden* \\ Departments of *Nephrology and ${ }^{8}$ Pathology, University Hospital Nijmegen, 6500 HB Nijmegen, The Netherlands; and ${ }^{\ddagger}$ Department of \\ Autoimmune Diseases, Central Laboratory of The Netherlands Red Cross Blood Transfusion Services, 1066 CX Amsterdam, The \\ Netherlands
}

\begin{abstract}
Histones can mediate the binding of DNA and anti-DNA to the glomerular basement membrane (GBM). In ELISA histone/DNA/anti-DNA complexes are able to bind to heparan sulfate (HS), an intrinsic constituent of the GBM. We questioned whether histone containing immune complexes are able to bind to the GBM, and if so, whether the ligand in the GBM is HS. Monoclonal antibodies (mAbs) complexed to nucleosomal antigens and noncomplexed mAbs were isolated from culture supernatants of four IgG anti-nuclear mAbs. All noncomplexed mAbs showed strong anti-nucleosome reactivity in ELISA. One of them showed in addition anti-DNA reactivity in noncomplexed form. The other three mAbs only showed anti-DNA reactivity when they were complexed to nucleosomal antigens.

After renal perfusion a fine granular binding of complexed $m A b s$ to the glomerular capillary wall and activation of complement was observed in immunofiuorescence, whereas noncomplexed mAbs did not bind. Immuno-electron microscopy showed binding of complexes to the whole width of the GBM. When HS in the GBM was removed by renal heparinase perfusion the binding of complexed $\mathrm{mAb}$ decreased, but did not disappear completely.

We conclude that anti-nucleosome $\mathrm{mAbs,}$ which do not bind DNA, become DNA reactive once complexed to nucleosomal antigens. These complexed $m A$ bs can bind to the GBM. The binding ligand in the GBM is partly, but not solely, HS. Binding to the GBM of immune complexes containing nucleosomal material might be an important event in the pathogenesis of lupus nephritis. (J. Clin. Invest. 1994. 94:568-577.) Key words: systemic lupus erythematosus - nephritis - anti-nucleosome - histones • heparan sulfate
\end{abstract}

This work was presented at the 26th Annual Meeting of the American Society of Nephrology, November 14-17, 1993 and published in abstract form (J. Am. Soc. Nephrol. 4:612).

Address correspondence to C. Kramers, M.D., University Hospital Nijmegen, Department of Nephrology, P.O. Box 9101, 6500 HB Nijmegen, The Netherlands.

Received for publication 20 December 1993 and in revised form 8 April 1994.

J. Clin. Invest.

(C) The American Society for Clinical Investigation, Inc.

0021-9738/94/08/0568/10 \$2.00

Volume 94, August 1994, 568-577

\section{Introduction}

Systemic lupus erythematosus (SLE) ${ }^{1}$ is an autoimmune disease characterized by the occurrence of numerous auto-antibodies directed primarily against nuclear antigens. Antibodies against double-stranded DNA (dsDNA) are regarded as highly specific for the disease (1). Nephritis is one of the most serious manifestations of the disease. Since nephritis is associated with a rise in titer of especially high avidity IgG anti-dsDNA and a depression of serum complement, it is generally assumed that these antibodies are involved in the pathogenesis of lupus nephritis and that they cause complement activation (2-4). Moreover, enrichment of these antibodies in renal and glomerular eluates of SLE patients and lupus mice has been found, sustaining the nephritogenic properties of these antibodies (5-7). How these antibodies bind in the glomerulus, however, is still unclear. The classical hypothesis that anti-DNA is deposited in the glomerular basement membrane (GBM) as DNA/anti-DNA immune complexes has been subject of much controversy (8). For instance, when artificially prepared DNA/anti-DNA immune complexes are injected in experimental animals, they show no affinity for the GBM, but instead are rapidly cleared by the liver (9-11). Indeed, it is not very likely that the negatively charged DNA in anti-DNA/DNA complexes would easily deposit in the negatively charged GBM (12). This controversy led Schmiedeke et al. (13) to the idea that binding of histones, which are highly positively charged DNA binding proteins might mediate the binding of DNA and anti-DNA. At the same time, analyzing the cross-reactivity of anti-DNA antibodies with heparan sulfate (HS), an intrinsic constituent of the GBM, we found that this cross-reactivity was due to histone/DNA containing immune complexes (14). The histone part in these complexes was responsible for the binding to HS. Furthermore, when we perfused subsequent histones, DNA and anti-DNA in a rat kidney, we observed a strong fine granular binding of antibodies to the capillary wall in immunofluorescence (IF), whereas after perfusion of DNA and anti-DNA, the binding was much less and restricted to the mesangium (15). The concept that histones may play a role in the initiation of lupus nephritis (reviewed recently in reference 16 ) was further substantiated

1. Abbreviations used in this paper: dsDNA, double-stranded DNA; GBM, glomerular basement membrane; HS, heparan sulfate; GAG, glycosaminoglycan; HSPG, heparan sulfate proteoglycan; IF, immunofluorescence; IEM, immuno-electron microscopy; NGS, normal goat serum; PLP, a mixture of $0.01 \mathrm{M}$ sodium periodate, $0.075 \mathrm{M}$ lysine $\mathrm{HCl}, 0.0375$ $\mathrm{M} \mathrm{Na}_{2} \mathrm{HPO}_{4}$ and $2 \%$ paraformaldehyde; SLE, systemic lupus erythematosus. 
by the finding of histone deposits in human and murine SLE nephritis $(17,18)$.

We realized however, that subsequent perfusion of purified histones, DNA and anti-DNA is a rather artificial system. It is not likely for histones and DNA to exist as separate entities in vivo. Indeed, in the circulation DNA is present bound to histones forming oligonucleosomal complexes $(19,20)$. When such nucleosomal material is released in the circulation of SLE patients, it is very likely that immune complexes are formed with anti-nuclear antibodies with specificity for either histones, nucleosomes or DNA. As we described before $(14,21)$ a similar complex formation occurs in supernatants of hybridomas secreting anti-nuclear antibodies. In these supernatants mAbs can be found complexed with nucleosomal antigens released from dying cells. That is why we chose to isolate immune complexes from such culture supernatants, to find out which characteristics of these immune complexes are associated with binding capacity in the GBM.

\section{Methods}

\section{Production of monoclonal antibodies}

mAbs were obtained by fusion of spleen cells from mice with spontaneous ([NZB $\times \mathrm{W}] \mathrm{F} 1, \mathrm{MRL} / \mathrm{Mp} / \mathrm{Ipr} / \mathrm{Ipr}$ ) or experimentally induced (parental-F1 chronic Graft Versus Host disease) SLE and screened for the presence of anti-dsDNA reactivity in ELISA or Farr assay as described previously (22) and new culture supernatants were prepared from which antibodies were purified. For the studies described in this paper, mAbs were selected which showed reactivity with HS in crude culture supernatants, since this reactivity is due to mAbs complexed to nucleosomal material (histones and DNA) as described previously (14). All selected mAbs belong to the IgG2a subclass.

\section{Preparation of immune-complexed and pure mAbs}

Hybridomas were grown in serum free conditions (IMDM; GIBCOBRL, Paisley, UK) supplemented with serum-free medium supplement, SF1 (Costar, Cambridge, MA) $2 \%$ vol/vol. Three purification procedures were used.

Procedure I (physiological conditions). Culture supernatants were applied to a protein-A Sepharose column (Pharmacia, Uppsala, Sweden) equilibrated with phosphate buffered saline (PBS).

Procedure II (high salt conditions). $\mathrm{NaCl}$, glycine and $\mathrm{NaOH}$ were added to culture supernatants to a final concentration of $3 \mathrm{M} \mathrm{NaCl}, 1.5$ $\mathrm{M}$ glycine, $\mathrm{pH} 8.9$, before applying to a protein-A Sepharose column which was equilibrated with a $3 \mathrm{M} \mathrm{NaCl}, 1.5 \mathrm{M}$ glycine, $\mathrm{pH} 8.9$ buffer.

Procedure III (DNase and high salt conditions). In this procedure the purification under high salt conditions was preceded by a DNase treatment. The culture supernatants were first treated with DNaseI (Boehringer Mannheim, Mannheim, Germany) with a final concentration of $40 \mu \mathrm{g} / \mathrm{ml}$ in the presence of $10 \mathrm{mM} \mathrm{MgCl}_{2}$. After $1 \mathrm{~h}$ incubation at $37^{\circ} \mathrm{C}$ the reaction was quenched with EDTA (Merck, Darmstadt, Germany) with a final concentration of $15 \mathrm{mM}$.

After each of these three different purification procedures immunoglobulins bound to the protein A column were eluted with a solution of $0.1 \mathrm{M}$ citric acid, $\mathrm{pH} 2.6$. The eluate was immediately brought to $\mathrm{pH}$ 7.4, dialyzed against PBS and stored at $-20^{\circ} \mathrm{C}$.

Using the third procedure, noncomplexed mAbs were obtained except for $\mathrm{mAb}$ No. 34. For this mAb still a fraction of the antibodies was complexed to nucleosomal antigens. The complexed and noncomplexed antibodies were separated with the use of a DNA-cellulose column (PL Biochemicals, Inc., Milwaukee, WI), which was equilibrated with PBS. Complexed antibodies retained on the column, whereas pure, noncomplexed antibodies were obtained in the column effluent.
Figure 1. SDS-PAGE of pure and complexed mAbs. (Lane $A$ ) Pure mAb No. 32 obtained via procedure III (only the heavy and light chains of Ig, but no histone bands are present). (Lane $B$ ) Complexed mAb No. 32 obtained via procedure I, containing both the Ig heavy and light chains and the four core histones, but not H1. (Lane $C$ ) Mixture of histones (Boehringer Mannheim). The H1, H2a, H2b, $\mathrm{H} 3$, and $\mathrm{H} 4$ bands are all present, and there is some contamination with other proteins in this histone mixture.

\section{Characterization of bound antigens in immune-complexed} $m A b s$

The presence of histones in complexed mAbs was determined by SDSPAGE ( $8-25 \%$ ) analysis followed by double silver staining (Phast gel system, Pharmacia). Histones were further identified by immunoblotting. The proteins were transferred to nitrocellulose by means of diffusion at $50^{\circ} \mathrm{C}$ using the Phast gel system (Pharmacia). Histones were identified using a rabbit anti-histone polyclonal antiserum diluted 1:100, prepared in our laboratory (15). The blot was developed with peroxidase-conjugated goat anti-rabbit Ig (ICN, Costa Mesa, CA) and stained with 4-chloro-1-naphtol. For the identification of DNA in the complexed mAbs, DNA was extracted by phenol-chloroform after proteolysis with proteinase $\mathrm{K}$ (Boehringer Mannheim). Proteolysis was performed by adding $100 \mu \mathrm{g}$ proteinase $\mathrm{K}$ in $5 \mu \mathrm{l}$ water to $300 \mu \mathrm{g} \mathrm{Ig}$, for $1 \mathrm{~h}$ at $50^{\circ} \mathrm{C}$. The DNA extract was $5^{\prime}$ end-labeled with $\left[{ }^{32} \mathrm{P}\right] \mathrm{dATP}$. Labeling was performed according to standard protocols using T4 polynucleotide kinase. After labeling DNA was analyzed on a $6 \%$ polyacrylamide gel (Sequagel-6; National Diagnostics, Atlanta, GA) using a labeled 123 bp ladder (Pharmacia) as a size marker.

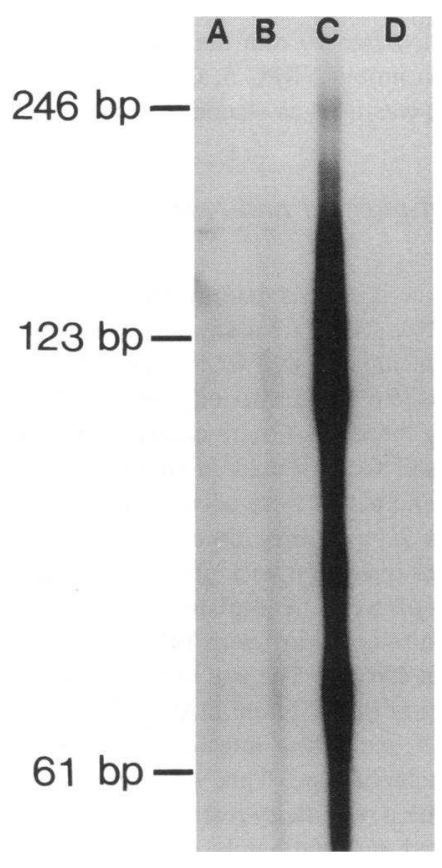

Figure 2. PAGE of DNA extract after labelling with $\left[{ }^{32} \mathrm{P}\right] \mathrm{dATP}$. Three purification procedures were used on culture supernatants of mAb No. 32. In lane $A$ hardly any DNA in the pure $\mathrm{mAb}$ (procedure III) is present. In complexed mAb No. 32, (procedure II) small amounts of DNA are detectable (lane $B$ ). Only after purification according to procedure I (lane $C$ ) large quantities of DNA are present in the complexed mAb. In lane $D$ a purified control mAb (WT1 mouse anti-human $\mathrm{CD} 7$ ) is shown in which no DNA is detectable. 
Table I. Composition, In Vitro Reactivity, and Glomerular Binding of the Different mAb Preparations

\begin{tabular}{|c|c|c|c|c|c|c|c|c|c|c|}
\hline \multirow[b]{2}{*}{ mAb nr procedure } & \multicolumn{3}{|c|}{ No. 2} & \multicolumn{3}{|c|}{ No. 32} & \multicolumn{3}{|c|}{ No. 34} & \multirow{2}{*}{$\frac{\text { No. } 42}{\text { II }}$} \\
\hline & I & II & III & I & II & III & I & II & III & \\
\hline \multicolumn{11}{|l|}{ Composition } \\
\hline Histones* & + & + & - & ++ & ++ & - & ++ & +++ & - & - \\
\hline DNA $^{\ddagger}$ & + & \pm & - & ++ & \pm & - & + & \pm & - & - \\
\hline \multicolumn{11}{|l|}{ In vitro reactivity } \\
\hline Farr $^{8}$ & 6 & 25 & 3 & 70 & 75 & 3 & 17 & 57 & 3 & 92 \\
\hline \multicolumn{11}{|l|}{ ELISA $^{\|}$} \\
\hline DNA & 178 & 227 & 36 & 98 & 100 & 1 & 178 & 200 & 16 & 25600 \\
\hline Histone & 55 & 90 & $<1$ & 4500 & 187 & 1 & 1777 & 800 & 494 & $<1$ \\
\hline Nucleosome & 3500 & 4800 & 3000 & 5000 & 7600 & 5400 & 7500 & 12000 & 12000 & 10000 \\
\hline HS & 11 & 36 & 4 & 9 & 9 & 1 & 13 & 20 & 1 & $<1$ \\
\hline Glomerular binding & + & + & - & ++ & +++ & - & ++ & +++ & - & - \\
\hline
\end{tabular}

Composition of bound complexes (Composition), reactivity in Farr assay and various ELISAs (In vitro reactivity) and glomerular binding (Glomular binding) of the different $\mathrm{mAb}$ preparations obtained after purification under physiological conditions (I), high salt conditions (II), or DNase treatment followed by high salt conditions (and in the case of mAb No. 34 additional separation of histone bound mAb on a DNA-cellulose column, see text) (III). * Histone content as assessed on SDS-PAGE; the intensity of the histone staining was scored semiquantitatively by comparing the intensity of the staining with that of the heavy and light chain. ${ }^{\ddagger}$ Presence of DNA fragments (of predominately 120 bp) as assessed after labeling with ${ }^{32} \mathrm{P}$. ${ }^{\S}$ Percent precipitation of labeled DNA per $12 \mu \mathrm{g}$ of IgG; values $\leqslant 3 \%$ are regarded as negative. " Titer/mg IgG. "Glomerular binding was assessed with indirect IF.

The immunoglobulin (Ig) concentration was determined in an ELISA, for which Nunc-immuno plates (Maxisorp F96; GIBCO BRL) were coated overnight at $4^{\circ} \mathrm{C}$ with goat anti-mouse Ig (Sigma Chemical Co., St. Louis, MO) diluted 1:80 in PBS, $100 \mu \mathrm{l}$ per well. Plates were washed five times with PBS containing $0.05 \%$ (vol/vol) Tween 20 and blocked with PBS containing $1 \% \mathrm{wt} /$ vol gelatin for $2 \mathrm{~h}$ at $37^{\circ} \mathrm{C}$. Samples were serially diluted in PBS $/ 1 \%$ gelatin and incubated for $1 \mathrm{~h}$ at $37^{\circ} \mathrm{C}$. Next, plates were washed again and $100 \mu \mathrm{l}$ of peroxidase-conjugated goat anti-mouse IgG2a diluted 1:750 (Southern Biotechnology Assoc. Inc., Birmingham, $\mathrm{AL}$ ) in $\mathrm{PBS} / 1 \%$ gelatin were added per well. After $1 \mathrm{~h}$ of incubation at $37^{\circ} \mathrm{C}$, the plates were washed. A freshly prepared substrate solution of $0.8 \mathrm{mg} / \mathrm{ml} 5^{\prime}$ aminosalicylic acid dissolved in 50 $\mathrm{mM}$ phosphate buffer, $\mathrm{pH} 6.0$, supplemented with $0.8 \mu \mathrm{l} / \mathrm{ml} 30 \% \mathrm{vol} /$ vol $\mathrm{H}_{2} \mathrm{O}_{2}$ was added to each well. After $30 \mathrm{~min}$ the $\mathrm{OD}$ at $450 \mathrm{~nm}$ was measured. An IgG2a myeloma protein (RPC 5; Cappel, Organon Technika NV, Turnhout, Belgium) was used as standard.

\section{Tests for antigen reactivity of purified and complexed anti-nuclear $m A b s$}

Anti-dsDNA assays. Anti-dsDNA activity was determined in the Farr assay and in an anti-dsDNA ELISA. The Farr assay was performed as described previously (23). In the anti-dsDNA ELISA photobiotinylated PUC9 plasmid DNA was used $(24,25)$. Briefly, plates (Maxisorb F96, GIBCO-BRL) used for the ELISA were coated overnight with streptavidin (Sigma Chemical Co.) diluted in distilled water $(150 \mu \mathrm{g}$ in $150 \mu \mathrm{l} /$ well $)$ at $4^{\circ} \mathrm{C}$. The plates were washed three times in PBS, containing $0.05 \%$ Tween 20 and three times with distilled water. Next, the plates were coated overnight with photobiotinylated DNA $\left(1 \mu \mathrm{g} / \mathrm{ml}\right.$ in PBS, $4^{\circ} \mathrm{C}, 150 \mu \mathrm{l} /$ well $)$. The plates were washed again and blocked for $2 \mathrm{~h}$ at room temperature with PBS containing $10 \%$ ( vol/vol) normal goat serum (NGS). The use of this blocking agent did not influence the binding of the different $\mathrm{mAb}$ preparations when compared to gelatin or BSA, excluding interference by putatively present nucleosomes or nucleohistone. This was further substantiated by the fact that mAbs with a specificity restricted to nucleosomes did not bind to plates coated with the batch of NGS used for blocking. Samples were serially diluted in PBS, $0.05 \%$ Tween 20 , containing 10\% NGS and incubated for $2 \mathrm{~h}$ at room temperature. Next, the plates were washed again and $100 \mu \mathrm{l}$ of peroxidase labeled rat mAb anti-mouse Ig (CLB-RM-19; CLB, Amsterdam, the Netherlands) diluted 1:1,000 in PBS were added per well. The plates were washed again and developed with 3,5,3',5'-tetramethylbenzidine (Merck), $100 \mu \mathrm{g} / \mathrm{ml}$ in $0.11 \mathrm{M}$ sodium acetate, $\mathrm{pH} 5.5$, containing $0.003 \% \mathrm{H}_{2} \mathrm{O}_{2}$. By adding $2 \mathrm{M} \mathrm{H}_{2} \mathrm{SO}_{4}, 100 \mu \mathrm{l} /$ well, color development was stopped after $15 \mathrm{~min}$ and $\mathrm{OD}$ at $450 \mathrm{~nm}$ was measured.

Anti-HS ELISA. HS, purified from bovine kidney, was purchased from Seikagugu Kogyo Ltd (Tokyo, Japan). Photobiotinylation of HS was performed in the same way as described for DNA (25). The concentration of HS was determined by the Farndale assay (26). The ELISA was performed identically as described for DNA. A mAb against HS (JM 403, described in reference 27) was used as a positive control.

Anti-histone ELISA. A mixture of the five histones ( $\mathrm{H} 1, \mathrm{H} 2 \mathrm{a}, \mathrm{H} 2 \mathrm{~b}$, $\mathrm{H} 3$, and $\mathrm{H} 4,2.5 \mu \mathrm{g} / \mathrm{ml}$ Boehringer Mannheim) in $0.1 \mathrm{M}$ Glycine $/ \mathrm{NaOH}$, $\mathrm{pH} 9,0.1 \mathrm{M} \mathrm{NaCl}$ was coated overnight at $4^{\circ} \mathrm{C}$ to Nunc-immuno plates. The plates were washed five times with PBS/0.05\% Tween 20 and blocked with $5 \%(\mathrm{vol} / \mathrm{vol})$ fetal calf serum (FCS) in PBS, $150 \mu \mathrm{l} /$ well, for $1 \mathrm{~h}$ at room temperature. Using the same methods as described for NGS we could exclude that the use of FCS influenced the results. The plates were washed again and samples serially diluted in PBS/ $0.05 \%$ Tween 20 , containing $5 \%$ FCS, were incubated ( $100 \mu \mathrm{l} /$ well) for $2 \mathrm{~h}$ at $37^{\circ} \mathrm{C}$. After washing the plates again, the procedure was identical to that for the anti-DNA ELISA.

Anti-nucleosome ELISA. Nucleosomes were a kind gift of Dr. L. Cebecauer (Research Institute of Rheumatic Diseases, Pieštany, Slovakia). They were purified from calf thymus according to standard protocols (28) and contained all five histones and no other proteins (as assessed by SDS-PAGE analysis) and DNA (as assessed on an agarose gel, data not shown). Nunc-immuno plates were coated with nucleosomes $2.5 \mu \mathrm{g} / \mathrm{ml}$, in $0.15 \mathrm{M} \mathrm{NaCl}, 0.15 \mathrm{M}$ trisodium citrate, $\mathrm{pH} 7.0$, for $1 \mathrm{~h}$ at room temperature $(100 \mu \mathrm{l} /$ well $)$. Plates were washed five times with distilled water and samples, serially diluted in PBS $/ 0.05 \%$ Tween 20 , containing $0.1 \%$ highly purified human serum albumin were 


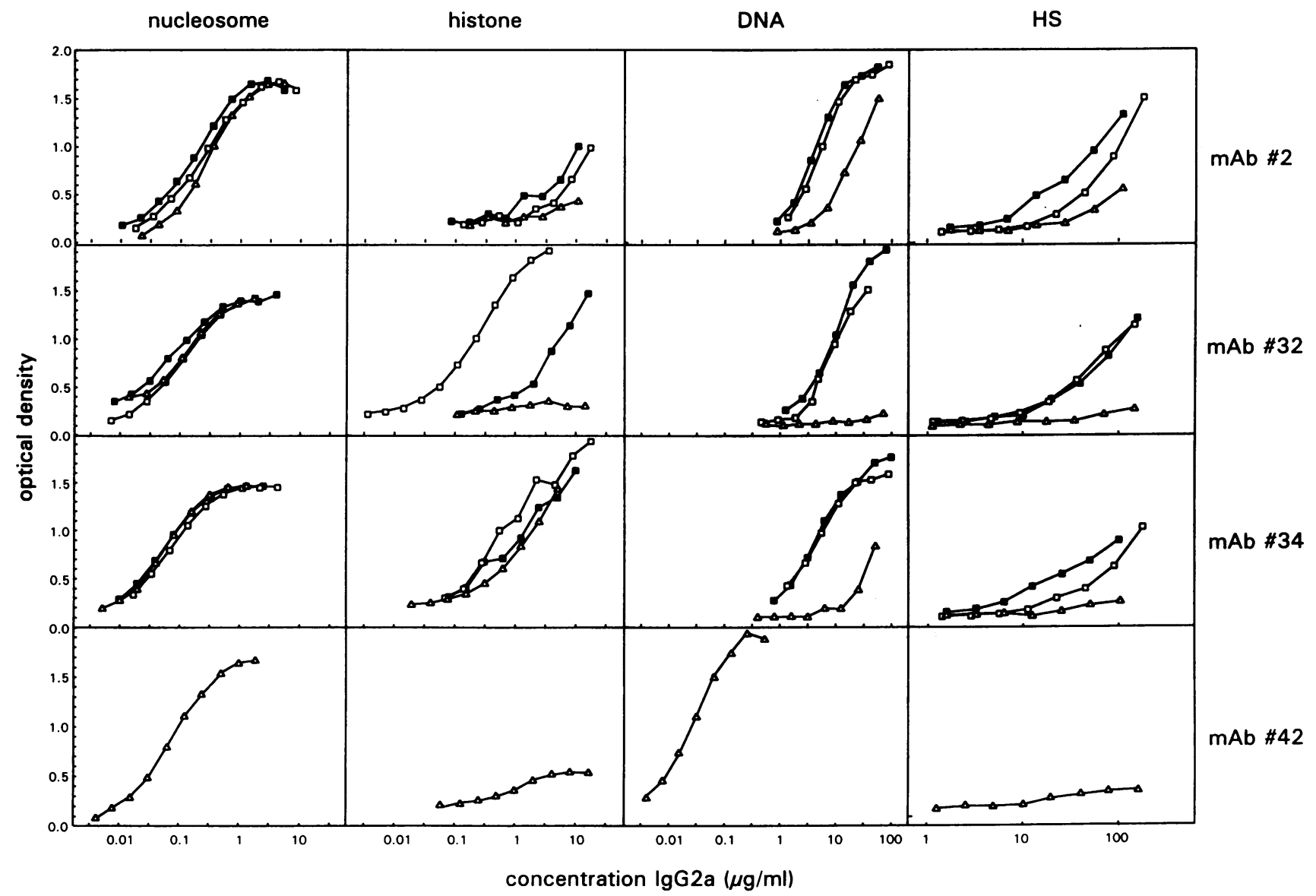

Figure 3. Reactivity of all described antibody preparations in the different ELISAs displayed over a wide range of antibody concentrations. The open triangles represent pure noncomplexed antibodies, open rectangles represent immune complexes containing both histones and DNA and closed rectangles represent immune complexes containing histones and only a small amount of DNA (see Table I, Composition). For mAbs No. 2, 32, and 34 pure noncomplexes antibodies only react with the intact nucleosome and pure noncomplexed mAb No. 42 reacts with both nucleosomes and DNA. The other three mAbs show only DNA reactivity once complexed to nucleosomal material.

incubated, $100 \mu \mathrm{l} /$ well, for $1 \mathrm{~h}$ at room temperature. After washing the plates five times with PBS/0.05\% Tween, further procedures were identical to the anti-DNA ELISA.

All ELISAs were titrated and the reciprocal of the dilution leading to an absorption of 1.0 at $450 \mathrm{~nm}$ was used as titer. All titers were expressed per mg of IgG2a.

\section{Preparation of reconstituted immune complexes}

Purified nucleosomes ( $30 \mu \mathrm{g}$ in $250 \mu \mathrm{l} \mathrm{PBS} / 0.1 \mathrm{mM}$ EDTA-1\% BSA) were mixed with non-complexed mAb No. 32 ( $250 \mu \mathrm{g}$ in $250 \mu \mathrm{l}$ PBS$1 \%$ BSA) obtained after purification procedure III. This mixture was incubated for $1 \mathrm{~h}$ at room temperature and used for renal perfusion studies in rats.

\section{Renal perfusion studies}

Male Wistar rats $(150 \mathrm{~g})$ were anesthetized by intraperitoneal administration of $0.15 \mathrm{ml}(9 \mathrm{mg})$ sodium pentobarbital (Narcovet, Apharmo, Arnhem, The Netherlands).

The renal perfusion was performed as described before (15). After perfusion the perfused kidney was taken out and immediately snap frozen in liquid $\mathrm{N}_{2}$ for immunofluorescence (IF).

In some experiments only a small part of the kidney was taken for IF. The remaining part was perfused with PLP for $10 \mathrm{~min}$ and prepared for immuno-electron microscopy (IEM) (for details, see below).
In additional experiments, after placing a ligature around the aorta between the origins of the left and the right renal artery, a 24-gauge catheter was placed in the aorta and the vena cava was not incised. The left kidney was flushed with $0.3 \mathrm{ml} 1 \%$ (wt/vol) BSA in PBS, followed by perfusion of pure $\mathrm{mAb}$ or immune complexes (150-500 $\mu \mathrm{g}$ in 500 $\mu 1$ ), which were allowed to bind for $3 \mathrm{~min}$. After flushing the left kidney again with $0.3 \mathrm{ml}$ PBS-1\% BSA, the ligature and catheter were removed to re-establish normal blood flow.

After $15 \mathrm{~min}$ the ligature was placed again and an 18-gauge catheter was placed in the aorta and the left kidney was flushed for 3 min with PBS-1\% BSA, before it was taken out and snap frozen in liquid $\mathrm{N}_{2}$ or prepared for IEM by PLP perfusion.

\section{Heparinase perfusion}

After placing the ligature and insertion of an 18-gauge catheter, the left kidney was flushed with saline for $2 \mathrm{~min}$. Next heparinase III (Sigma Chemical Co.) $60 \mathrm{U}$ in saline containing $1 \% \mathrm{BSA}$ and $5 \mathrm{mM} \mathrm{CaCl}$ was perfused at a flow rate of $1 \mathrm{ml} / \mathrm{min}$. The enzyme was allowed to act for $4 \mathrm{~min}$. Next the kidney was flushed with PBS-1\% BSA for 3 $\mathrm{min}$. This heparinase perfusion was followed by perfusion of complexed mAbs. The kidney was further processed as described above. To control for nonspecific changes, perfusion was performed with buffer without heparinase and subsequent with complexed mAbs. Experiments were repeated three times with different amounts of perfused complexed 


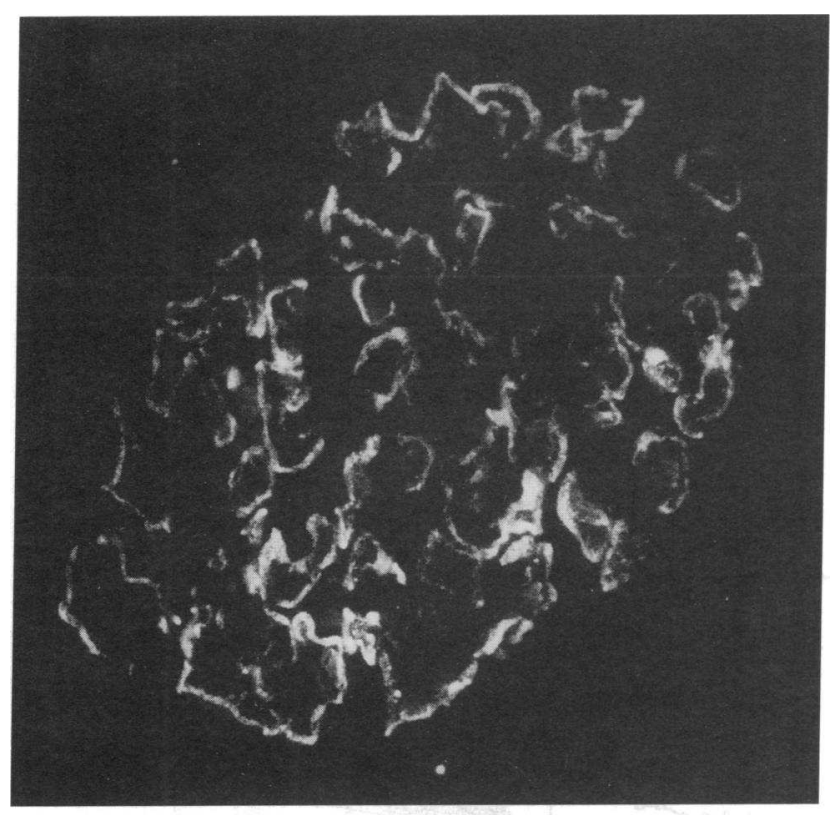

Figure 4. Direct immunofluorescence of the glomerular binding after perfusion with mAb No. 32 complexed to histones. Binding of complexed mAb in the capillary wall of the glomerulus can be observed $(\times 600)$.

mAbs (ranging from $200-600 \mu \mathrm{g}$ IgG2a). The expression of glomerular HS was assessed with IF by the anti-HS mAb JM 403 (described in reference 27).

\section{Immunohistology}

Immunofluorescence. Direct IF was performed on 2- $\mu \mathrm{m}$ cryostat sections from perfused rat kidneys using a $\mathrm{F}(\mathrm{ab})_{2}$ FITC-labeled sheep antimouse IgG (Cappel, Organon Technika NV) diluted 1:750 in order to detect deposition of perfused mouse Ig. Sections were also stained with a rabbit anti histone polyclonal antiserum diluted 1:600. This antiserum was prepared as described before (15). After rinsing with PBS bound rabbit antibodies were visualized using a FITC-labeled mouse antirabbit $\operatorname{IgG}(\mathrm{H}+\mathrm{L})$ diluted 1:40 (Jackson Laboratories Inc., West Groove, PA). In experiments in which the blood flow was restored after perfusion, sections were also stained with FITC-labeled goat anti-rat C3 diluted 1:40 (Nordic, Tilburg, the Netherlands).

In the experiments in which heparinase was perfused before perfusion of complexed mAbs, sections were stained with a mouse IgM antiHS-glycosaminoglycan (HS-GAG) side chain mAb (JM 403, described in reference 27) and with a goat anti-human HS-core protein antiserum cross reacting with rat HS-proteoglycan (HSPG, described in reference 29). As secondary antibodies FITC labeled goat anti-mouse IgM (Fc) (Nordic) diluted 1:100 or FITC-labeled rabbit anti-goat Ig (De Beer Med. BV, Hilvarenbeek, the Netherlands) diluted 1:500 were used. The sections were also stained with a rabbit anti-rat (L2) laminin polyclonal antiserum diluted 1:400 and with a goat anti-human collagen IV polyclonal antiserum cross-reacting with rat diluted 1:200, which were both prepared in our laboratory, followed by FITC-labeled mouse anti-rabbit Ig (Jackson Laboratories Inc.) diluted 1:40 and by FITC labeled rabbit anti-goat Ig (de Beer Med BV) diluted 1:500, respectively, as second antibodies. Deposition of mouse Ig was evaluated using a $F(a b)_{2}$ FITClabeled sheep anti-mouse IgG as described. The Ig depositions were semiquantitatively scored on blinded sections in 30 glomeruli per kidney on a scale from $0-4+$ by two independent observers.

After all staining procedures, sections were embedded in Aquamount (BDH Ltd, Poole, England) and examined with a Zeiss fluorescence microscope.

Immuno-electron microscopy. Tissue was prepared for IEM by perfusion of the kidneys during $10 \mathrm{~min}$ with a mixture of $0.01 \mathrm{M}$ sodium periodate, $0.075 \mathrm{M}$ lysine $\mathrm{HCl}, 0.0375 \mathrm{M} \mathrm{Na}_{2} \mathrm{HPO}_{4}$ and $2 \%$ paraformaldehyde (PLP). Thereafter the kidney was cut into small pieces $(5 \times 5$ $\times 1 \mathrm{~mm}$ ) and immersed in PLP for another $3 \mathrm{~h}$. Next, the tissue was washed in PBS for 30 min and cryoprotected by immersion in $80 \%$ wt/ vol sucrose in PBS for $1 \mathrm{~h}$, before they were snap frozen in liquid $\mathrm{N}_{2}$.

$20-\mu \mathrm{m}$ sections were incubated with a peroxidase labeled antimouse Ig diluted 1:20 (Dakopatt, Copenhagen, Denmark). After three washes in PBS, the sections were preincubated in diaminobenzidine medium containing $0.6 \mathrm{wt} / \mathrm{vol}$ TRIS for $10-15 \mathrm{~min}$, followed by diami-
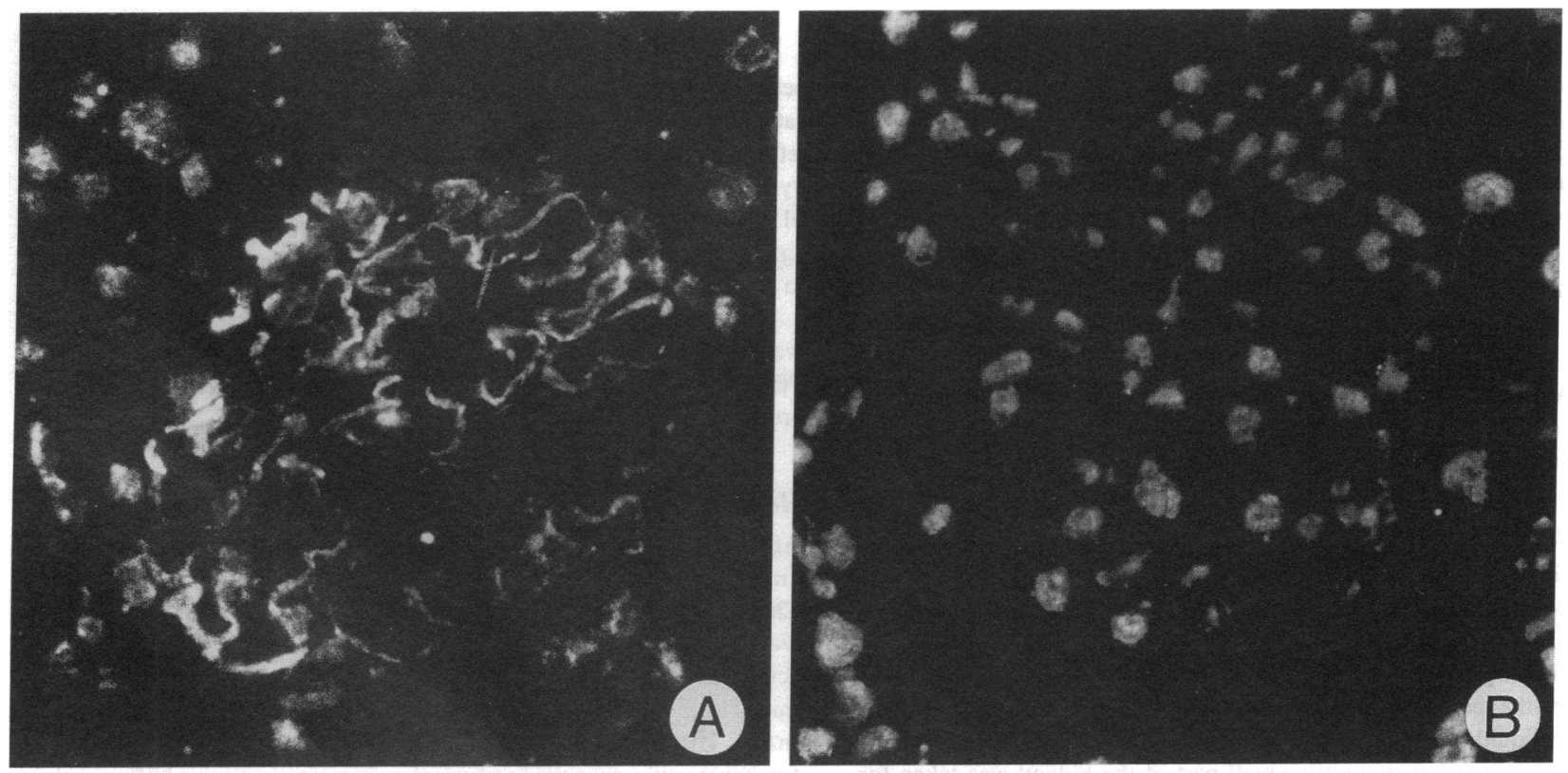

Figure 5. Indirect immunofluorescence of histones in a kidney perfused with mAb No. 32 complexed to histones $(A)$. A positive staining is seen in the nuclei and along the glomerular capillary wall. After perfusion with pure mAb No. 32 only nuclear staining is observed $(B)(\times 500)$. 


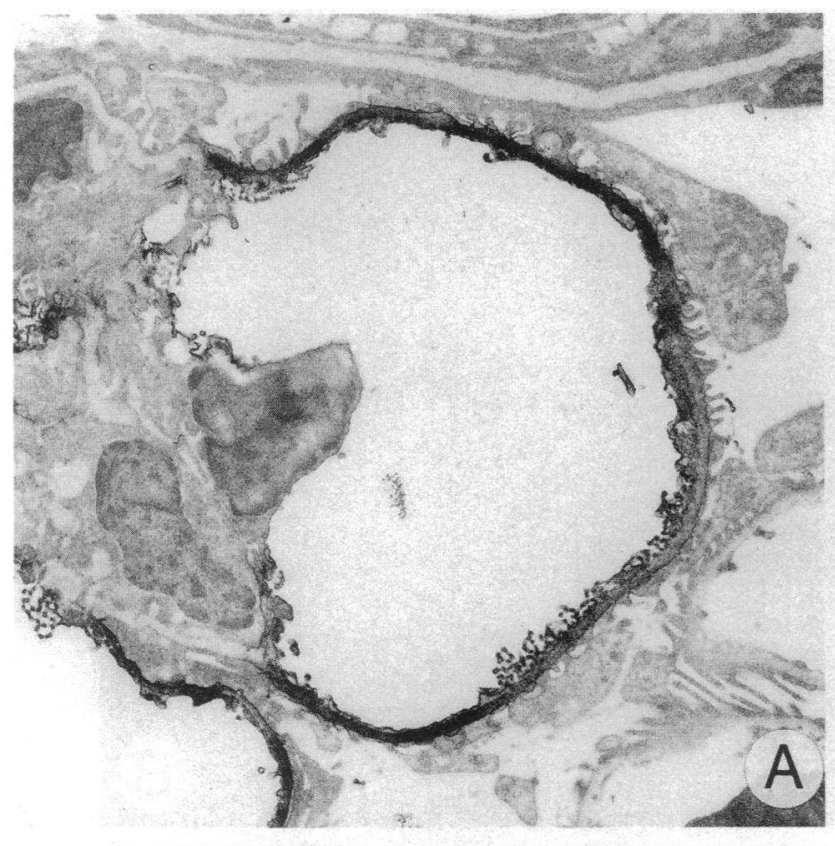

tions. The presence of histones was visualized by SDS-PAGE (Fig. 1, showing the results for mAb No. 32) and immunoblotting (data not shown). DNA fragments were demonstrated in the complexed $\mathrm{mAb}$ after labeling with ${ }^{32} \mathrm{P}$. The greater part of this DNA had a size of $\sim 120 \mathrm{bp}$ but also some larger ( $240 \mathrm{bp}$ ) and smaller fragments were seen (Fig. 2). Immune complexes containing histones and only a small amount of DNA were obtained after procedure II for mAbs No. 2, 32, and 34. A summary of the composition of the complexed material bound to the mAbs is given in Table I (Composition).

Reactivity of complexed and pure mAbs in ELISA and Farr assay. The reactivities of the different preparations of these $m A b s$ in the Farr assay and in the different ELISAs are given in Table I (In vitro reactivity). In Fig. 3 the results of the different ELISAs are displayed in a dose effect manner over a wide range of antibody concentrations. Anti-DNA reactivity in the Farr assay and in the ELISA was found after purification under physiological conditions (procedure I) and comparable with that observed in crude culture supernatants (data not shown). DNA binding became even greater after reduction of the amount of DNA in the complex (procedure II). After complete removal of bound nuclear material from these mAbs, mAbs No. 2, 32, and 34 lost their anti-DNA reactivity almost completely, whereas No. 42 remained strongly positive. A more or less similar picture emerged when the different preparations were tested on histones, i.e., positive in complexed form and negative in purified form, except for mAb No. 34. Completely different was the reactivity towards nucleosomes, the reactivity remained unaltered after purification. From these data it can be concluded that mAb Nos. 2 and 32 recognize an epitope expressed only on the intact nucleosome, mAb No. 34 reacts with an epitope on the intact nucleosome although in pure form it also reacts with histones, suggesting that for the recognition of the epitope on nucleosomes histone related antigens are involved. Finally, mAb No. 42 primarily reacts with dsDNA, which also explains the reactivity with the intact nucleosome.

Glomerular binding after perfusion of complexed and pure Figure 6. Immuno-electron microscopy after perfusion with mAb No. 32 complexed to histones. There is binding of complexed mAb throughout the width of the GBM and only limited deposition on mesangial or endothelial cells $(A)$. In a detail $(B)$ the GBM binding of these complexes is visualized more clearly $(A, \times 5,000 ; B, \times 20,000)$.

nobenzidine with addition of $\mathrm{H}_{2} \mathrm{O}_{2}$ to a final concentration of $0.001 \%$ $\mathrm{vol} / \mathrm{vol}$. The sections were washed in distilled water, postfixed in 0.1 $\mathrm{M}$ phosphate buffered $2 \% \mathrm{wt} / \mathrm{vol} \mathrm{OsO}_{4}$ for $30 \mathrm{~min}$ at room temperature, dehydrated, and embedded in Epon 812. Thin sections were prepared on a LKB ultratome, and examined unstained in an electron microscope (Jeol 1200 EX2, Jeol Europe BV).

\section{Results}

Identification of histone and DNA in complexed and purified $m A b s$. From a panel of mAbs originally identified as anti-DNA mAbs (described in reference 22) mAbs No. 2, 32, 34, and 42 were used in this study. Purified noncomplexed mAbs were obtained after procedure III for mAbs No. 2 and 32. while for mAb No. 34 this procedure had to be supplemented by purification on a DNA-cellulose column. For mAb No. 42 noncomplexed antibodies were obtained after procedure II. Immune complexes containing the core histones $(\mathrm{H} 2 \mathrm{a}, \mathrm{H} 2 \mathrm{~b}, \mathrm{H} 3$, and H4) and DNA were obtained after procedure I, except for mAb No. 42 which did not bind protein $A$ under physiological condiAbs. The glomerular binding that occurred after renal perfusion of the different $\mathrm{mAb}$ preparations is summarized in Table I (Glomerular binding). From these perfusion experiments it becomes clear that binding only occurs if the mAbs are complexed. A representative example of the observed binding is given in Fig. 4. In purified form none of the mAb showed any binding. The major determinant for GBM binding was the presence of histones in the complex, irrespective of the amount of DNA present. In fact for mAbs No. 32 and 34 the magnitude of the binding was even larger for preparations obtained after purification under high salt conditions (procedure II, reducing the amount of bound DNA considerably), compared with preparations obtained after purification under physiological conditions (procedure I; not removing the DNA from the nucleosomal particle). This suggests that reduction of the DNA content within the nucleosome enhances the glomerular binding. The involvement of histones in this GBM binding is further substantiated by indirect IF using an anti-histone antiserum showing besides nuclear staining, a fine granular deposition of histones along the capillary wall after perfusion of complexed $\mathrm{mAb}$ (Fig. $5 A$ ), but no capillary wall staining after perfusion of pure noncomplexed mAb (Fig. $5 B$ ). At the ultrastructural level the Ig binding occurred through the whole width of the GBM, with only very limited binding to the endothelium or the mesangium 

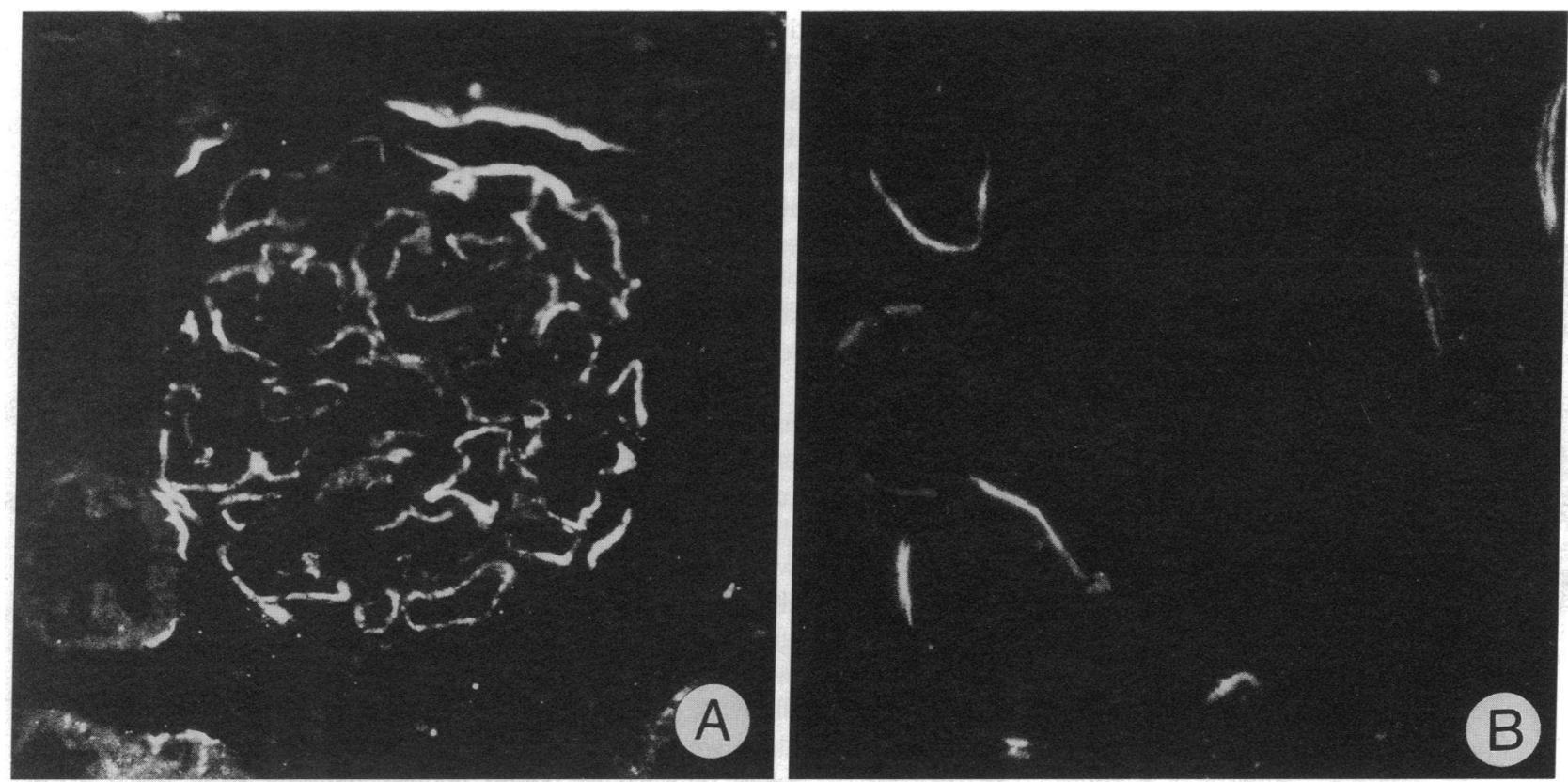

Figure 7. Direct immunofluorescence for rat $\mathrm{C} 3$ after perfusion with $\mathrm{mAb}$ No. 32 complexed to histones, followed by restoration of the blood flow for $15 \mathrm{~min}$. Note deposition of rat C3 in the capillary wall of the glomerulus $(A)$. When pure mAb No. 32 was perfused followed by restoration of the blood flow, there was no deposition of rat complement in the glomerulus $(B)$, only staining of the basal part of the proximal tubular cells, which is normal in rat kidneys $(\times 480)$.

(Fig. 6, $A$ and $B$ ). That this glomerular binding may have pathogenic potential can be derived from the observation that restoration of the renal circulation after perfusion of complexed $\mathrm{mAbs}$ leads to $\mathrm{C} 3$ deposition along the capillary wall in a pattern identical to that of the Ig deposits (Fig. 7).

Glomerular binding after perfusion of nucleosome reconstituted complexes. When purified mAbs were reconstituted with purified nucleosomes, glomerular binding was observed in IF after perfusion, which was comparable with the binding seen after perfusion of complexed antibodies obtained from culture supernatants. A representative example of the observed binding is given in Fig. 8. When the noncomplexed $\mathrm{mAb}$, used for the

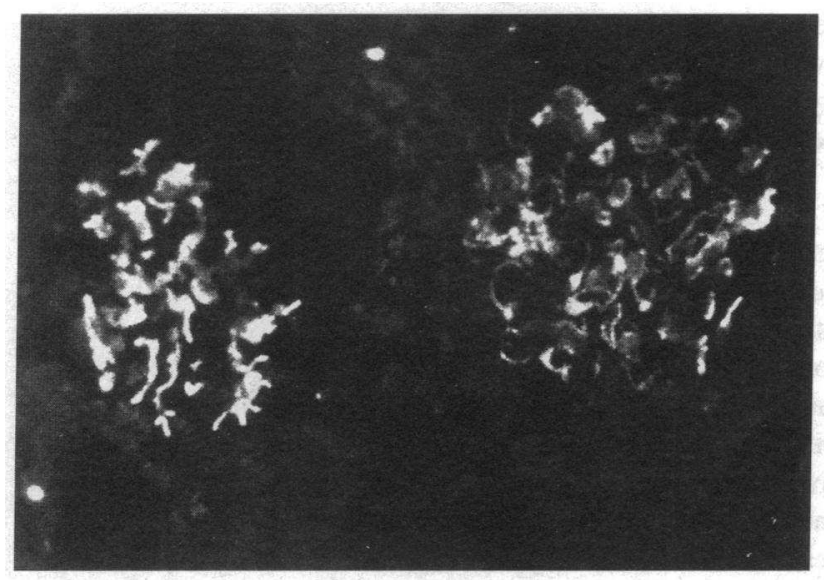

Figure 8. Direct immunofluorescence of the glomerular binding after perfusion of a reconstituted immune complex of pure noncomplexed mAb No. 32 (obtained after procedure III) and highly purified nucleosomes. Binding of complexed $\mathrm{mAb}$ in the capillary wall of the glomerulus can be observed $(\times 300)$. reconstitution of these immune complexes, was perfused, no binding was observed, indicating that it was the nucleosome in the complex, which mediated the glomerular binding of the antibodies. In addition perfusion of nucleosomes with a nonrelevant mAb WT1 directed against human CD7 did not lead to glomerular antibody binding.

Binding of complexed mAbs after heparinase perfusion. To investigate the significance of GBM-HS in the glomerular binding of complexed $\mathrm{mAb}$, heparinase was perfused before $\mathrm{mAb}$ perfusion. After heparinase, staining of the HS-GAG side chain within the GBM had almost disappeared completely, whereas staining of the HSPG-core protein was intact, indicating that the HS-GAG side chain was effectively removed from the core protein by this procedure (Fig. 9). Staining of other GBM components, like laminin or collagen IV also remained intact (data not shown). If histone-containing immune complexes were perfused after heparinase perfusion, binding of the $\mathrm{mAb}$ decreased, but did not disappear totally (Table II, Fig. 9), suggesting that $\mathrm{HS}$ is not the only ligand through which these immune complexes can bind to the GBM as we have already suggested before (15).

\section{Discussion}

In previously reported experiments from others (13) and from our laboratories $(14,15,30)$, it was shown that anti-dsDNA antibodies can bind to the GBM via an intermediate bridge of histones and DNA, in which the histone part is responsible for the binding to anionic sites in the GBM (for review see reference 16). Since our previous studies were performed with subsequent separate perfusion of histones, DNA, and purified antiDNA, we now extend these observations in the present study by using $\mathrm{mAb}$ to nucleosomal antigens. These mAbs were se- 

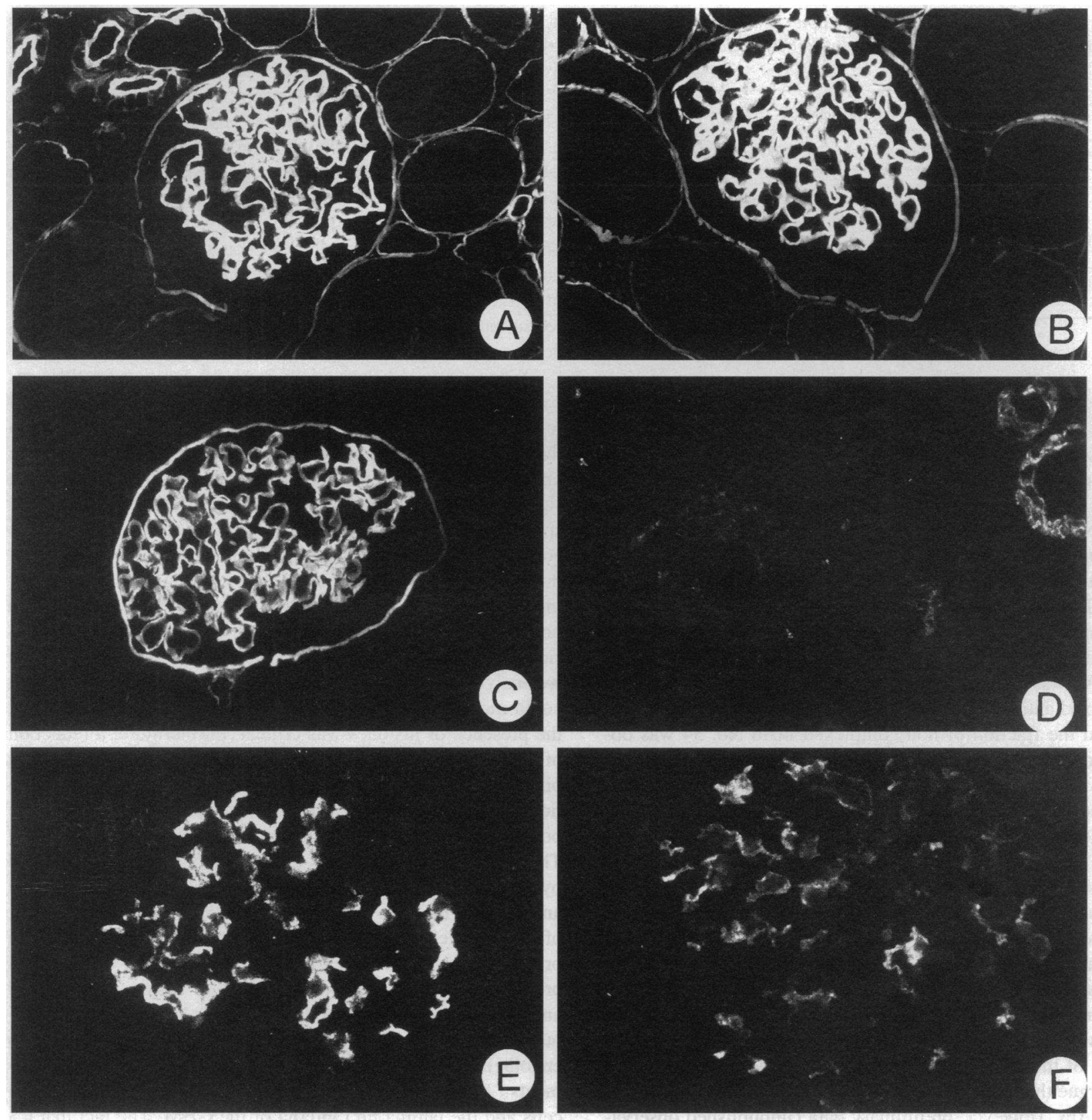

Figure 9. Indirect immunofluorescence of a kidney perfused with heparinase compared with a control perfusion. After control perfusion the staining of HSPG-core protein $(A)$ and HS-GAG side chain $(C)$ is intact. In the kidney perfused with heparinase the staining of the HSPG-core protein is still intact $(B)$, whereas the staining of the HS-GAG side chain has disappeared $(D)$. When mAb No. 32 complexed to histones is perfused after heparinase or a control perfusion, the binding of complexed $\mathrm{mAb}$ is decreased in the heparinase perfused kidney $(F)$ as compared with the control perfusion $(E)(A-D, \times 350 ; E, \times 400 ; F, \times 480)$.

lected from a panel of mAbs on the basis of their binding to HS. This reactivity was found using crude hybridoma culture supernatants, since we have shown in previous experiments that HS reactivity is due to antibodies complexed to nuclear antigens (14). To evaluate whether these complexed mAbs could bind to the GBM, we performed perfusion studies with complexed and noncomplexed antibody preparations and with reconstituted complexes composed of purified $\mathrm{mAb}$ and nucleosomes. The GBM binding was related to the composition of the antibody bound material and the reactivity of the $\mathrm{mAb}$ in vitro.
The purification procedures confirm our previous observations that during hybridoma culture nuclear antigens become bound to the mAbs, since we could identify core histones and DNA in the complex bound to the mAb after isolation under physiological conditions. Purification under high salt conditions led to a significant removal of DNA from the bound complex for mAbs No. 2, 32, and 34, whereas after this procedure mAb No. 42 did not contain any nucleosomal material at all. Why, after purification under high salt conditions the DNA content in the complex with mAbs No. 2, 32, and 34 is significantly 
Table II. Influence of Heparinase Perfusion (Removing HS from the GBM) on the Subsequent Binding of Perfused Complexed mAB No. 32

\begin{tabular}{cccc}
\hline \multirow{2}{*}{$\begin{array}{c}\text { Amount of complexed } \\
\text { mAb perfused }(\mu \mathrm{g} \text { IgG2a) }\end{array}$} & HS-GAG & HSPG-core & \\
\cline { 2 - 3 } & & $\begin{array}{c}\text { GBM staining } \\
\text { Decrease of } \\
\text { GBM binding }\end{array}$ \\
\hline & - & + & $\%$ \\
300 & - & + & 81 \\
600 & - & + & 76 \\
\hline
\end{tabular}

reduced, but the histone content not, is not completely clear. It may be related to antigen binding properties of these mAbs, since mAb No. 42 is directed against DNA and the other three are directed against nucleosomal epitopes. In the case of two of these three mAbs (No. 2 and 32) pure antibody was obtained after DNase pretreatment, suggesting that the residual DNA in the complex observed after high salt purification only, plays a role in the binding of the antibody. In any case the combined use of DNase pretreatment and high salt conditions yielded noncomplexed mAbs No. 2 and 32. In contrast to this, a subfraction of $\mathrm{mAb} 34$ was still bound to histones after this procedure. This mAb was further purified using a DNA-cellulose column. Complexed antibodies, containing histones, retained on the column and the fraction of non-complexed mAb No. 34 was obtained in the effluent and used for further studies.

The in vitro analysis of the antigen reactivity of complexed and noncomplexed $\mathrm{mAb}$ indicates that binding of nucleosomal material can strongly influence the displayed specificity. In general the Farr assay is regarded as the most appropriate test to detect high avidity anti-dsDNA antibodies (22). However, our results show that Farr positivity can be the result of binding of complexes composed of nucleosomal material and anti-nucleosome antibodies, since effective removal of these nuclear antigens leads to disappearance of the binding in the Farr assay. This Farr reactivity seems to be the result of the presence of histones within the nucleosomal particle, which is conceivable because of the DNA binding properties of these proteins. One could argue that this phenomenon is a peculiar characteristic of these mAbs. However, preliminary data (unpublished observations ) indicate that this is also true for polyclonal auto-antibodies from SLE patients. These observations however, do not reduce the usefulness of the Farr assay in the follow-up of SLE patients, since Farr positivity might be due to the presence in the circulation of auto-antibodies complexed to nucleosomes which we regard as potentially nephritogenic. Furthermore, these observations might explain why Farr positivity is associated with onset and/or exacerbation of lupus nephritis (4) and with anti-HS reactivity in SLE patients $(31,32)$.

The in vitro analysis shows in addition that anti-DNA reactivity both in the Farr assay and in the ELISA and anti-histone reactivity can be a feature of antibodies primarily directed against (neo-) epitopes expressed on nucleosomes. The presence of anti-nucleosomal antibodies in SLE has been described before (33-35). In addition, mAbs derived from lupus mice have been described which showed a much higher reactivity towards histone-DNA complexes, than to histones or DNA alone $(36,37)$, and recently Losman et al described a mAb which only reacted with the intact nucleosome and not with any of the subnucleosomal particles (38). This reactivity is similar to what we observed with purified mAbs No. 2 and 32 which also react with a neo-epitope on the intact nucleosome. The reactivity of purified mAb No. 34 is somewhat different, since it still reacted in non-complexed form with histones. From these data it is tempting to speculate that the epitope This $\mathrm{mAb}$ recognizes within the nucleosomes is different from that recognized by mAbs No. 2 and 32, since these became negative in the histone ELISA once purified. Our observations support the possibility that antinucleosomal autoantibodies might be present much more frequent in SLE than we appreciate today. This is further underlined by the recent report that nucleosomes are a major immunogen for pathogenic auto-antibody inducing T-helper cells (39).

When we tested the various mAb preparation for their capacity to bind to the GBM, we found that the mAbs complexed to nucleosomal antigens (mAbs No. 2, 32 and 34) did bind to the GBM, while the noncomplexed, pure mAbs did not bind at all. To exclude that additional components from the culture supernatants copurified with the nucleosomal material are responsible for this binding, we prepared nucleosome-antibody complexes by reconstituting pure noncomplexed $\mathrm{mAb}$ (procedure III) with highly purified nucleosomes and again saw binding to the GBM. The observation that non-complexed mAb did not bind to the GBM does not support a direct binding to intrinsic constituents as has been suggested before $(8,40,41)$. When we analyzed the composition of the nucleosomal material which could mediate the binding of mAb to the GBM, we found that the presence of histones was critical. Furthermore, a reduction of the amount of DNA within the nucleosome enhanced this binding. This observation raises the possibility that partial digestion of the nucleosome by DNase enhances the nephritogenic potential of anti-nuclear antibodies complexed to nucleosomes. The involvement of histones in lupus nephritis is substantiated by the recent demonstration of histone deposits in both human and murine lupus nephritis $(17,18,42)$. The GBM binding of the complexes containing nucleosomal material used in the present study was different from the binding that we observed previously after subsequent perfusion of histones, DNA and anti-DNA. In our present study we found a localization throughout the whole width of the GBM and hardly any binding to endothelial or mesangial cells, whereas in our previous experiments (15) the majority of the binding occurred to endothelial cells and the lamina rara interna of the GBM. The fact that C3 deposition is induced suggests the nephritogenic potential of this binding. Our heparinase perfusion experiments show that HS is an important target for this nucleosome mediated antibody binding, but also that it is not the only anionic ligand within the GBM. Additional studies are needed to delineate further these other binding moieties. It is tempting to speculate that this nucleosome binding to HS is the explanation for our recent observation that in human (43) as well as in murine lupus nephritis (44) the HS staining in the GBM, as assessed by an anti-HS mAb, has almost completely disappeared, moreover since nucleosomes were able to inhibit the binding of this anti$\mathrm{HS} \mathrm{mAb}$ to $\mathrm{HS}$ in vitro.

In summary, we found that nucleosomal material can mediate the binding of antibodies to the GBM and that complexes composed of nucleosomal antigens and anti-nucleosome antibodies may show anti-DNA reactivity, even in a Farr-type assay which previously was thought to specifically detect high avidity 
antibodies to DNA only. Binding of these nucleosome containing complexes to the GBM, might be a first step, leading to lupus nephritis.

\section{Acknowledgments}

This study was supported by a grant from the Dutch Kidney Foundation (C91.1081) and from the Dutch League against Rheumatism (90 CR $287)$. Dr. van den Born and Dr Berden are supported by a grant from the EC Biomed I program (BMH1-CT92-1766).

\section{References}

1. Tan, E. M. 1982. Autoantibodies to nuclear antigens (ANA): their immunobiology and medicine. Adv. Immunol. 33:167-240.

2. Swaak, A. J. G., L. A. Aarden, L. W. Statius van Eps, and T. E. W. Feltkamp. 1979. Anti-dsDNA and complement profiles as prognostic guides in SLE. Arthritis Rheum. 22:226-235.

3. Koffler, D., V. Agnello, R. Thoburn, and H. G. Kunkel. 1971. SLE, prototype of immune complex nephritis in man. J. Exp. Med. 134:169S-179S.

4. ter Borg, E. J., G. Horst, E. J. Hummel, P. C. Limburg, and C. G. M. Kallenberg. 1990. Predictive value of rises in anti-double-stranded DNA antibody levels for disease exacerbations in systemic lupus erythematosus: a long term prospective study. Arthritis Rheum. 33:634-643.

5. Winfield, J. B., I. Faiferman, and D. Koffler. 1977. Avidity of anti-DNA antibodies in serum and IgG glomerular eluates from patients with systemic lupus erythematosus. J. Clin. Invest. 59:90-96.

6. Kalunian, K. C., N. Panosian-Sahakian, F. M. Ebling, A. H. Cohen, J. S. Louie, J. Kaine, and B. H. Hahn. 1989. Idiotypic characteristics of immunoglobulins associated with systemic lupus erythematosus. Arthritis Rheum. 32:513-522.

7. Termaat, R. M., K. J. M. Assmann, J. P. H. F. van Son, H. B. P. M. Dijkman, R. A. P. Koene, and J. H. M. Berden. 1993. Antigen-specificity of antibodies bound to glomeruli of mice with systemic lupus erythematosus-like syndromes. Lab. Invest. 68:164-173.

8. Eilat, D. 1985. Crossreactions of anti-DNA antibodies and the central dogma of lupus nephritis. Immunol. Today. 6:123-127.

9. Emlen, W., and M. Mannik. 1982. Clearance of circulating DNA/antiDNA immune complexes in mice. J. Exp. Med. 155:1210-1217.

10. Taylor, R. P., G. Kujala, J. C. Edberg, P. Foreman, J. S. Davis IV, and E. Wright. 1986. The kinetics of clearance of human antibody/dsDNA immune complexes from rabbit circulation. Effects of dsDNA size, rheumatoid factor, and reduction and alkylation of the antibodies. J. Immunol. 136:3785-3792.

11. Emlen, W., and G. Burdick. 1988. Clearance and organ localization of small DNA anti-DNA immune complexes in mice. J. Immunol. 140:1816-1822.

12. Fournié, G. J. 1988. Circulating DNA and lupus nephritis. Kidney Int. 33:487-497.

13. Schmiedeke, T. M. J., F. W. Stöckl, R. Weber, Y. Sugisaki, S. R. Batsford, and A. Vogt. 1989. Histones have high affinity for the glomerular basement membrane. J. Exp. Med. 169:1879-1894.

14. Termaat, R. M., K. Brinkman, F. van Gompel, L. P. W. J. van de Heuvel, J. Veerkamp, R. J. T. Smeenk, and J. H. M. Berden. 1990. Cross-reactivity of monoclonal anti-DNA antibodies with heparan sulfate is mediated via bound DNA/histone complexes. J. Autoimmun. 3:531-545.

15. Termaat, R. M., K. J. M. Assmann, H. B. P. M. Dijkman, R. J. T. Smeenk, and J. H. M. Berden. 1992. Anti-DNA antibodies can bind to the glomerulus via two distinct mechanisms. Kidney Int. 42:1363-1371.

16. Kramers, C., M. N. Hylkema, R. M. Termaat, K. Brinkman, R. J. T. Smeenk, and J. H. M. Berden. 1993. Histones in lupus nephritis. Exp. Nephrol. 1:224-228.

17. Stöckl, F. W., S. Muller, S. Batsford, T. Schmiedeke, R. Waldherr, K. Andrassy, Y. Yugisaki, K. Nakabayashi, T. Nagasawa, B. Rodriguez-Iturbe, U. Donini, and A. Vogt. 1994. A role for histones and ubiquitin in lupus nephritis. Clin. Nephrol. 41:10-17.

18. Schmiedeke, T. M. J., F. W. Stöckl, S. Muller, Y. Sugisaki, S. Batsford, R. Woitas, and A. Vogt. 1992. Glomerular immune deposits in murine lupus models may contain histones. Clin. Exp. Immunol. 90:453-458.

19. Rumore, P. M., and C. R. Steinman. 1990. Endogenous circulating DNA in systemic lupus erythematosus. J. Clin. Invest. 86:69-74.

20. Fournié, G. J., L. Bret, P. Belenguer, S. Muller, C. Alary, C. Rollet, and H. Benoist. 1992. Physicochemical characterization of plasma DNA. Lupus 1 (suppl. 1):186. (Abstr.)

21. Brinkman, K., R. M. Termaat, J. De Jong, H. G. Van den Brink, J. H. M. Berden, and R. J. T. Smeenk. 1989. Cross-reactive binding patterns of monoclonal antibodies to DNA are often caused by DNA/anti-DNA immune complexes. Res. Immunol. 140:595-612.

22. Smeenk, R. J. T., K. Brinkman, H. G. Van den Brink, and A. A. A Westgeest. 1988. Reaction patterns of monoclonal antibodies to DNA. J. Immunol. 140:3786-3792.

23. Aarden, L. A., and R. J. T. Smeenk. 1981. Measurements of antibodies specific for DNA. In Immunological Methods. Vol. 2. I. Lef kovits and B. Pernis, editors. Academic Press, New York. 75.

24. Emlen, W., P. Jarusiripipat, and G. Burdick. 1990. A new ELISA for the detection of double-stranded DNA antibodies. J. Immunol. Methods. 132:91-101.

25. Hylkema, M. N., H. Huygen, C. Kramers, Th. J. van der Wal, J. De Jong, M. C. J. van Bruggen, A. J. G. Swaak, J. H. M. Berden, and R. J. T. Smeenk. 1994. Clinical evaluation of a modified ELISA, using photobiotinylated DNA, for the detection of anti-DNA antibodies. J. Immunol. Methods. 170:93-102.

26. Farndale, R. V., C. A. Sayers, and A. J. Barrett. 1982. A direct spectrophotometric microassay for sulphated glycosaminoglycans in cartilage cultures. Connect. Tiss. Res. 9:247-248.

27. van den Born, J., L. P. W. J. van den Heuvel, M. A. H. Bakker, J. H. Veerkamp, K. J. M. Assmann, and J. H. M. Berden. 1992. A monoclonal antibody against GBM heparan sulfate induces an acute selective proteinuria in rats. Kidney Int. 41:115-123.

28. Kornberg, R. D., J. W. La Pointe, and Y. Lorch. 1989. Preparation of nucleosomes and chromatin. Methods Enzymol. 170:3-14.

29. van den Heuvel, L. P. W. J., J. van den Born, T. J. A. M. van de Velden, J. H. Veerkamp, L. A. H. Monnens, C. H. Schroder, and J. H. M. Berden. 1989. Isolation and partial characterization of heparan sulfate proteoglycan from the human glomerular basement membrane. Biochem. J. 264:457-465.

30. Brinkman, K., R. M. Termaat, J. H. M. Berden, and R. J. T. Smeenk. 1990. Anti-DNA antibodies and lupus nephritis: the complexity of crossreactivity. Immunol. Today. 11:232-234.

31. Termaat, R. M., K. Brinkman, J. C. Nossent, A. J. G. Swaak, R. J. T. Smeenk, and J. H. M. Berden. 1990. Anti-heparan sulphate reactivity in sera from patients with systemic lupus erythematosus with renal or non-renal manifestations. Clin. Exp. Immunol. 82:268-274.

32. Kramers, C., R. M. Termaat, E. J. ter Borg, M. C. J. van Bruggen, C. G. M. Kallenberg, and J. H. M. Berden. 1993. Higher anti-heparan sulphate reactivity during SLE exacerbations with renal manifestations. A long term prospective analysis. Clin. Exp. Immunol. 93:34-38.

33. Burlingame, R. W., R. L. Rubin, R. S. Balderas, and A. N. Theofilopoulos. 1993. Genesis and evolution of anti-chromatin autoantibodies in murine lupus implicates T-dependent immunization with self antigen. J. Clin. Invest. 91:1687-1695.

34. Totoritis, M. C., E. M. Tan, E. M. McNally, and R. L. Rubin. 1988. Association of antibody to histone complex $\mathrm{H} 2 \mathrm{a}-\mathrm{H} 2 \mathrm{~b}$ with symptomatic procainamide-induced lupus. N. Engl. J. Med. 318:1431-1436.

35. Burlingame, R. W., and R. L. Rubin. 1991. Drug-induced anti-histone autoantibodies display two patterns of reactivity with substructures of chromatin. J. Clin. Invest. 88:680-690.

36. Jacob, L., J. D. Viard, B. Allenet, M. F. Anin, F. B. H. Slama, J. Vanderkerckhove, J. Primo, J. Markovits, F. Jacob, J. F. Bach, J. B. Le Peco, and D. Louvard. 1989. A monoclonal anti-double-stranded DNA autoantibody binds to a 94-kDa cell-surface protein on various cell types via nucleosomes or a DNAhistone complex. Proc. Natl. Acad. Sci. USA. 86:4669-4673.

37. Losman, M. J., T. M. Fasy, K. E. Novick, and M. Monestier. 1992. Monoclonal autoantibodies to subnucleosomes from a MRL/Mp- $+/+$ mouse. $J$. Immunol. 148:1561-1569.

38. Losman, J. A., T. M. Fasy, K. E. Novick, M. Massa, and M. Monestier. 1993. Nucleosome-specific antibody from an autoimmune MRL/Mp-Ipr/Ipr mouse. Arthritis Rheum. 36:552-560.

39. Mohan, C., S. Adams, V. Stanik, and S. K. Datta. 1993. Nucleosome, a major immunogen for pathogenic autoantibody-inducing T cells of lupus. J. Exp. Med. 177:1367-1381.

40. Madaio, M. P., J. Carlson, J. Cataldo, A. Ucci, P. Migliorini, and O. Pankewycz. 1987. Murine monoclonal anti-DNA antibodies bind directly to glomerular antigens and form immune deposits. J. Immunol. 138:2883-2889.

41. Raz, E., M. Brezis, E. Rosenmann, and D. Eilat. 1989. Anti-DNA antibodies bind directly to renal antigens and induce kidney dysfunction in the isolated perfused rat kidney. J. Immunol. 142:3076-3082.

42. Akashi, Y., S. Oshima, Y. Suzuki, J. Nishiyama, J. Okada, and N. Yoshizawa. 1993. Glomerular deposition of histone and ubiquitin in kidney biopsy tissue of patients with SLE. J. Am. Soc. Nephrol. 4:672. (Abstr.)

43. van den Born, J., L. P. W. J. van den Heuvel, M. A. H. Bakker, J. H. Veerkamp, K. J. M. Assmann, J. J. Weening, and J. H. M. Berden. 1993. Distribution of GBM heparan sulphate proteoglycan core protein and side chains in human glomerular diseases. Kidney Int. 43:454-463.

44. van den Born, J., C. Kramers, M. A. H. Bakker, M. C. J. van Bruggen, K. J. M. Assmann, and J. H. M. Berden. 1992. Decreased anti-heparan sulfate staining of the glomerular basement membrane in lupus nephritis. Possible role for histones. Kidney Int. 42:793. (Abstr.) 